INFO ARTIKEL

Riwayat Artikel:

Diterima : 01 Januari 2020

Disetujui : 28 Februari 2020

\title{
GEOGRAFI
}

\section{OPTIMALISASI DATA DIGITAL TERRAIN MODEL UNTUK PEMBUATAN 3D FISIOGRAFIS DAN GEOMORFOLOGI GEOPARK SILOKEK}

\author{
Affan Nurman Muharram ${ }^{1}$, Firdaus Ramadani ${ }^{1}$, Beben Graha Putra ${ }^{1}$ \\ ${ }^{1}$ Program Studi Geografi, Universitas Negeri Padang \\ (छ) affanmuharram1@gmail.com
}

\begin{abstract}
ABSTRAK
Geopark Silokek merupakan salah satu dari Geopark yang memiliki bentangan fisiografis menarik yaitu memiliki batuan tua yang berumur 350 juta tahun yang terdiri dari batu gamping (karst), batuan sedimen, batuan metamorf, dan intrusi granit. Tujuan penelitian ini adalah untuk mengidentifikasi bentukan fisiografis yang terdapat di kawasan Geopark Silokek dengan memanfaatkan data Digital Terrain Model (DTM) serta pengamatan langsung dilapangan. Data yang digunakan dalam penelitian ini adalah Data Demnas dengan akurasi 8 m, peta Geologi dari Kementerian ESDM, dan Citra Spot 6. Metode penelitian dengan menggunakan pemodelan 3 Dimensi (3D) melalui pemanfaatan nilai elevasi ketinggian sehingga dapat menarik peta yang semula datar. Hasil penelitian menunjukkan bahwa Geopark Silokek memiliki kenampakan fisiografis yang berbeda berdasarkan kondisi geologi, hidrologi, dan ekologinya. Pemodelan 3D akan memperjelas kenampakan fisiografis yang terdapat di kawasan Geopark Silokek serta dapat menunjang potensi pariwisata di Geopark Silokek.
\end{abstract}

Kata Kunci: Digital Terrain Model, Fisiografis, Geomorfologi, Geopark.

\section{PENDAHULUAN}

Kawasan Geopark Nasional Silokek yang secara Administrasi termasuk kedalam salah satu daerah yang berada di sepanjang Kanagarian Muaro Silokek dan Durian Gadang dengan luas kawasan $300 \mathrm{~km}$ yang berlokasi di Kacamatan Sijunjung dan Kecamatan Sumpur Kudus Kabupaten Sijunjung. Geopark Nasional Silokek memiliki banyak keragaman geologi yang unik dan umur bebatuan yang sangat tua yaitu sekitar 350 Juta Tahun yang lalu. Seperti pegunungan dengan struktur geologi berupa patahan dan lipatan yang intensif serta memiliki aliran sungai jika kita lihat di navigasi citra seperti membelah bukit yang kokoh. Keunikan lainnya yaitu terdapat batuan singkapan yang berada di pinggiran sungai yang terdiri dari batuan sedimen dan batuan metamorf sehingga menarik untuk dipelajari.
Secara geologi, Silokek sangat menarik karena telah melewati tiga era dalam skala waktu geologi yang tercermin dalam susunan batuan yang membentuk kawasan. Batuan tertua dalam kawasan ini terbentuk pada masa Paleozoikum yang tepatnya pada periode permian (299-252 Juta Tahun yang lalu) dan Periode Carboniferus (359299 Juta Tahun yang lalu). kondisi morfologi Silokek terlihat berupa tebing batuan gamping (Karst) dengan kemiringan sudut sekitar $70^{\circ}$ dan bergelombang pada ketinggian 200-400 meter. Sedangkan pada daerah dengan ketinggian 500600 meter merupakan puncak kawasan Karst.(Kusuma,2019)

Keunikan dan keberagaman geologi Kawasan Geopark Silokek telah ditetapkan dan diakui sebagai kawasan Geopark Nasional melalui usulan 
Balitbang Provinsi Sumatera Barat dan Surat Keputusan Bupati Sijunjung Nomor: 188.45/404/KPTS-BPT-2016 tentang Penetapan Kawasan wisata strategis dan Destinasi Pariwisata di Kabupaten Sijunjung. Kemudian Penetapan silokek sebagai kawasan Geopark Nasional ditandai dengan penyerahan sertifikat Geopark Nasional oleh Menteri Pariwisata Arief Yahya kepada Bupati Sijunjung, Yuswir Arifin di Museum Tambang Antam Kecamatan Nanggung kabupaten Bogor pada tanggal 30 November 2018. setelah ditetapkan, maka harapan selanjutnya ialah dapat mendaftar sebagai UNESCO Global Geopark Network.

Geopark itu sendiri adalah sebuah kawasan yang memiliki unsur-unsur geologi dimana masyarakat setempat diajak berperan serta untuk melindungi dan meningkatkan fungsi warisan alam, termasuk nilai arkeologi, ekologi dan budaya yang ada di dalamnya (UNESCO,2006) menurut penjelasan UNESCO, unsur utama geopark terbagi menjadi 3 yaitu unsur geodiversity, biodiversity, dan cultural diversity. Konsep asas geopark menurut UNESCO adalah pembangunan ekonomi secara mapan melalui warisan geologi atau geotourism. Tujuan dan sasaran dari geopark adalah untuk melindungi keragaman bumi (geodiversity) dan konvervasi lingkungan, pendidikan dan ilmu kebumian secara luas. Berdasarkan definisi UNESCO, geopark dapat dipahami melalui beberapa aspek seperti sebagai suatu kawasan, sebagai sarana pengenalan warisan bumi, sebagai kawasan lindung warisan bumi, sebagai tempat pengembangan geowisata, sebagai sarana kerjasama yang efektif dan efisien dengan masyarakat lokal, dan sebagai tempat implementasi aneka ilmu pengetahuan dan teknologi.

Sistem Informasi Geografis (SIG) adalah sistem informasi yang khusus mengelola data yang memiliki informasi spatial (bereferensi keruangan) atau dalam arti luasnya SIG adalah sistem pengelolaan, penyimpanan, pemrosesan (manipulasi), analisis dan penayangan data secara

spatial terkait dengan muka bumi. Komponen SIG terdiri dari lima komponen yang bekerja secara terintegrasi yaitu perangkat keras (hardware), perangkat lunak (data), manusia, dan metode. SIG memiliki lima proses yaitu input data, manipulasi data, manajemen data, query, analisis proximity, analisis overlog, dan visualisasi. Saat ini SIG Telah Banyak di gunakan oleh pakar ilmu pakar kebumian (geoscientis) untuk mengintegrasikan data geologi, geomorfologi, geokimia dan geofisika.

Sejak perkembangan teknologi di bidang survei dan pemetaan semakin berkembang, kebutuhan akan data survei pemetaan semakin tinggi dan menuntut terdapatnya informasi geospasial yang lebih teliti dan visualisasi yang sebatas dua Dimensi (2D) berkembang ke arah tiga Dimensi (3D). Tampilan 3 dimensi suatu wilayah akan dapat membantu perencanaan secara matang serta data yang dapat digunakan untuk berbagi macam simulasi dan analisis .dengan meningkatkan penggunaan komputer dalam rekayasa dan pengembangan cepat dimensi komputer. Digital Terrain Model (DTM) menjadi alat yang ampuh untuk sejumlah besar aplikasi di bumi dan ilmu teknik.

Ditinjau dari bentuk pola penyebaran titik ini dapat di klasifikasi kan menjadi: DTM Tidak beraturan (irregular DTM),DTM grid ,DTM profil ,dan DTM Kontur (Setya,2001 mengutip Hendriatiningsih,1987).

\section{METODOLOGI PENELITIAN}

Penelitian ini adalah penelitian deskriptif, dengan menggunakan data primer yang diambil dari survei lapangan studi literatur dan analisis secara spasial. Lokasi penelitian Berada di daerah di Kanagarian Muaro Silokek, Kecamatan Sijunjung, Kabupaten Sijunjung, Sumatera Barat. Alat dan Bahan Penelitian yang digunakan dalam penelitian ini dijabarkan pada Tabel 1 .

Teknik analisis data yang digunakan dalam penelitian ini adalah (1) Analisis Deskriptif, merupakan teknik analisis yang dipakai untuk menganalisis data dengan mendeskripsikan atau menggambarkan data-data yang sudah dikumpulkan seadanya tanpa ada maksud membuat generalisasi dari hasil penelitian. Penelitian ini menggunakan metode analisis deskriptif. Analisis ini digunakan untuk melihat kenampakan fisiografis yang ada di kawasan geopark silokek 
dengan bantuan hasil perekaman GPS. (2) Analisis

Digital Terrain Model (DTM), DTM merupakkan Analisis untuk melihat beberapa aspek yang terjadi di daratan seperti kemiringan dan elevasi daratan .namun seiring berkembang nya waktu DTM juga mampu untuk diaplikasikan kedalam dunia lautan jadi secara umum DTM Didefinisikan sebagai sekumpulan set data yang mewakili distribusi spasial dari berbagai jenis informasi tentang sebuah medan lokasi (fahrulian dkk .,2016 mengutip miller dan lafflame 1885) (3) Overlay peta merupakan kemampuan menampilkan suatu peta digital dan peta digital lainya beserta atributatributnya. Proses overlay digunakan sebagai peramu berbagai indikator yang berasal dari petapeta tematik hingga menjadi satu peta analisis. Peta analisis ini pada akhirnya digunakan sebagai dasar penarikan kesimpulan untuk kasus yang sedang di teliti. Metode ini digunakan untuk penghubungan data DEM terhadap citra SPOT 6 dan SHP Peta Geomorfologi dalam membuat peta 3 Dimensi.

Tabel 1. Alat dan Bahan yang digunakan dalam penelitian

\begin{tabular}{|c|c|c|}
\hline No. & $\begin{array}{c}\text { Alat dan } \\
\text { Bahan }\end{array}$ & Penjelasan \\
\hline 1 & GPS & $\begin{array}{l}\text { GPS adalah sistem navigasi yang menggunakan satelit yang didesain agar dapat } \\
\text { meneyediakan posisi secara instan, kecepatan dan informasi waktu dihampir } \\
\text { semua tempat di muka bumi, setiap saat dan dalam kondisi cuaca apapun. GPS } \\
\text { juga sering digunakkan untuk keperluan Sistem Informasi Geografis, seperti untuk } \\
\text { membuat peta, mengukur jarak perbatasan, atau bisa dijadikan sebagai referensi } \\
\text { pengukuran suatu wilayah. }\end{array}$ \\
\hline 2 & DemNas & $\begin{array}{l}\text { DEM Nasional (DEMNAS) dibangun dari berbagai sumber data meliputi IFSAR } \\
\text { (Resolusi } 5 \mathrm{~m} \text { ), TERRASAR-X (Resolusi } 5 \mathrm{~m} \text { ) dan ALOS PALSAR (Resolusi } \\
11,25 \mathrm{~m} \text { ), dengan menambahkan data Masspoint hasil Stereo-platting. Resolusi } \\
\text { Spasial DEMNAS adalah 0,27-arcsecond, dengan menggunakan datum vertikal } \\
\text { EGM 2008. }\end{array}$ \\
\hline 3 & $\begin{array}{l}\text { Citra } \\
\text { SPOT-6 }\end{array}$ & $\begin{array}{l}\text { Citra SPOT-6 dikembangkan oleh AIRBUS Defence and Space dan diluncurkan } \\
\text { pada } 9 \text { september 2012. satelit SPOT-6 (dan juga bersama SPOT-7) menggantikan } \\
\text { posisi SPOT-4 dan SPOT-5 yang telah beroperasi sejak tahun } 1998 \text { dan } 2002 . \\
\text { selain itu stasiun bumi dan antariksanya juga telah dirancang dengan perbaikan } \\
\text { kinerja dibandingkan sebelumnya terutama dalam hal aktifitas akuisisi khusus } \\
\text { yang meliputi ketepatan pengiriman dan akuisisi. }\end{array}$ \\
\hline 4 & ArcScene & $\begin{array}{l}\text { ArcScene adalah aplikasi Visualisasi 3D yang memungkinkan untuk melihat data } \\
\text { GIS dalam 3D. ArcScene memungkinkan untuk melapisi banyak lapisan data } \\
\text { dalam lingkungan 3D. Fitur ditempatkan dalam 3D dengan memberikan informasi } \\
\text { ketinggian dari geometri fitur,atribut fitur, properti layer, atau permukaan 3D yang } \\
\text { ditentukan, dan setiap layer dalam tampilan 3D dapat ditangani secara berbeda. } \\
\text { data dengan referensi yang berbeda akan diproyeksikan ke proyeksi umum, atau } \\
\text { data dapat ditampilkan hanya dengan menggunakan koordinat relatif. ArcScene } \\
\text { juga sepenuhnya terintegrasi dengan lingkungan geoprocessing, menyediakan } \\
\text { akses ke banyak alat dan fungsi analisis. }\end{array}$ \\
\hline
\end{tabular}

\section{HASIL DAN PEMBAHASAN}

\section{A. Fisiografis dan Geomorfologi Geopark Silokek}

Dalam penelitian ini menerapkan metode analisis deskriptif untuk mengidentifikasi kenampakan fisiografis pada kawasan Geopark Silokek. Geopark silokek sendiri memiliki beberapa fenomena-fenomena geologi yang menarik sehingga dapat mempengaruhi kondisi morfologi dan kenampakan fisiografis yang ada disana. Beberapa morfologi diantaranya yaitu bentang lahan struktural, karst, aluvial dan denudasional. Berdasarkan hasil survey lapangan dengan pengumpulan data primer lapangan ke lokasi penelitian, pengumpulan titik koordinat di setiap pengamatan menggunakan hasil perekaman GPS sehingga dapat di peroleh sebaran titik pengamatan dan kenampakan 
fisiografi seperti yang ditampilkan pada Gambar 1.

Gambar 1 menampilkan titik-titik koordinat hasil pengamatan yang telah diolah menggunakan ArcScene dengan metode analisis DTM, sehingga dapat menciptakan reprentasi digital topografi dan medan bentang lahan.
Setiap titik pengamatan diperlihatkan bukti kenampakan morfologinya menggunakan data DTM. Kenampakan geomorfologi dari peta DTM akan dapat diamati yang menunjukkan tiga bentanglahan, yaitu bentang lahan karst, daerah singkapan batuan dan bentang lahan Aluvial

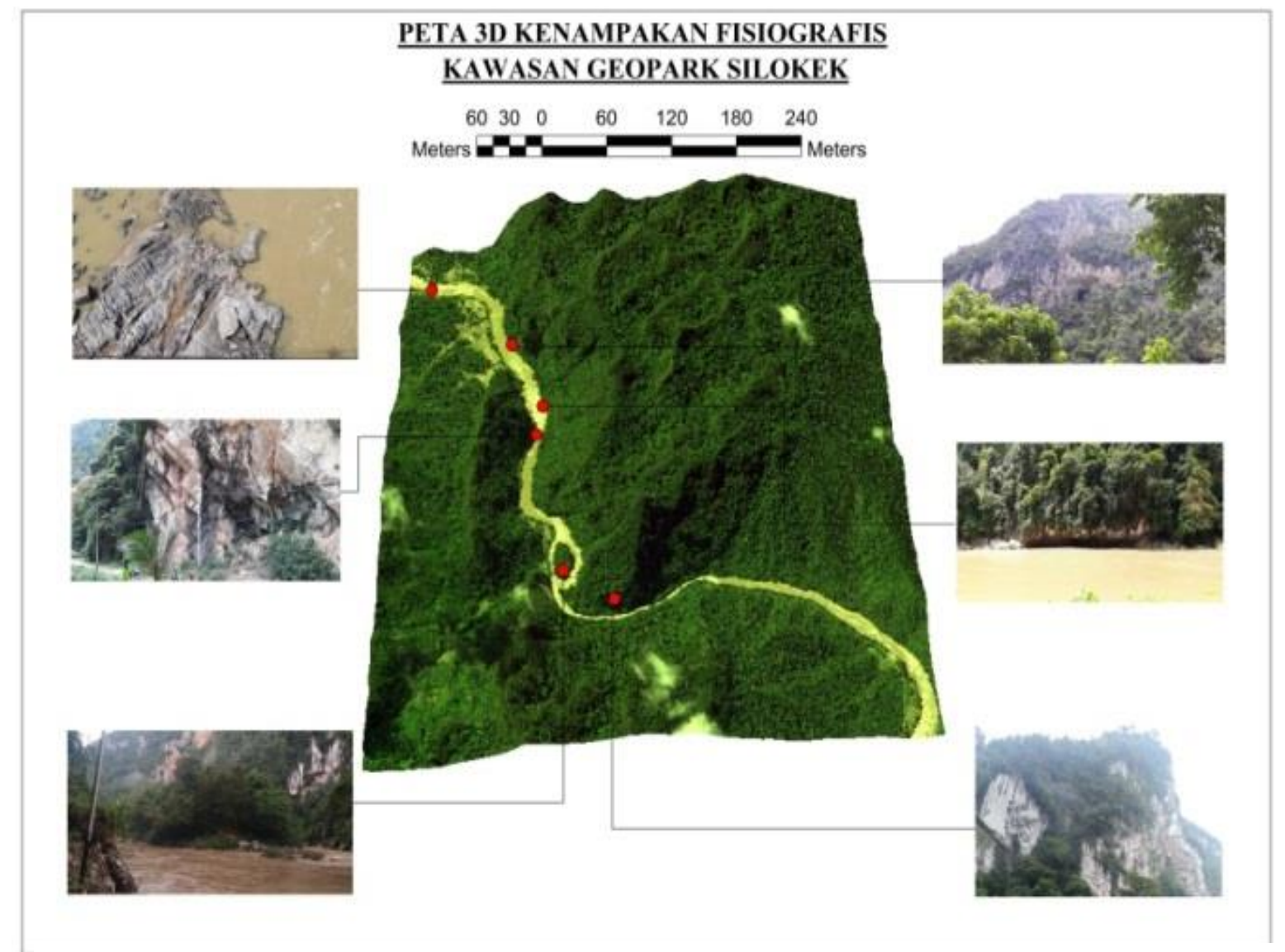

Gambar 1. Peta 3 Dimensi Kenampakan Geomorfologi

(Sumber : Analisis Data, 2019)

Selain metode analisis DTM, penelitian ini juga menggunakan ArcMap dengan metode analisis DEM, sehingga dapat menampilkan kenampakan bentang lahan di kawasan silokek melalui kenampakan topografi yang dihasilkan. Data DEM tersebut dihubungkan terhadap citra SPOT 6 dalam membuat peta 3D lalu menghasilkan peta overlay seperti pada Gambar 2 .

Berdasarkan hasil analisa pada bentuk topografi kawasan Geopark Silokek pada gambar 2, dapat diketahui bentuk-bentuk lahan yang berada di wilayah kawasan Geopark Silokek yang menunjukkan bentuk lahan struktural, asal Aluvial, asal denudasional, dan karst.

\section{Bentuklahan asal struktural}

Bentuklahan asal struktural terbentuk karena adanya proses endogen atau proses tektonik yang berupa pengangkatan, perlipatan dan pensesaran. Berdasarkan hasil analisis bentuk topografi pada peta geomorfologi, kawasan silokek ini memiliki 3 satuan bentuklahan asal struktural antara lain:

a) Blok Perbukitan Antiklinal merupakan bentanglahan yang berbentuk sebuah punggung bukit yang telah mengalami perlipatan yang kemiringan sayapnya kearah saling berlawanan dan saling menjauh (bentuk concav dengan cembung keatas). dibeberapa tempat kawasan lipatan, terdapat sungai yang mengalir memotong daerah pelipatan melalui suatu 
lembah sempit dan dalam (Lihat Gambar 2), tentu saja sungai ini sudah ada sebelum kelipatan terjadi yang kemudian mengiris daerah pelipatan sejalan dengan proses pelipatan tersebut sehingga sungai ini termasuk pola aliran tipe anteseden (Suharini,2014). Morfologi antiklin umumnya dijumpai didaerah cekungan sedimen yang telah mengalami pengangkatan dan perlipatan. Pada peta kawasan silokek ditandai warna coklat.

b) Blok perbukitan patahan merupakan bentang lahan yang terdiri dari bukit-bukit yang dibatasi oleh bidang patahan. Patahan tersebut dapat terlihat pula secara lansung di singkapan batuan, terutama pada singkapan tebing-tebing jalan atau tebing sungai yang tersingkap akibat kikisan aliran sungai (Lihat Gambar 1). Pada peta kawasan silokek ditandai warna ungu tua.

c) Gawir sesar merupakan bentuk lahan berbentuk bukit yang salah satu lerengnya merupakan bidang sesar. Morfologi ini dicirikan oleh bukit memanjang dengan perbedaan ketinggian yang cukup ekstrim antara bagian yang datar dan bagian bukit. Pada peta kawasan silokek ditandai warna merah muda (pink).

\section{Bentuklahan asal Fluvial}

Bentuklahan asal Fluvial terbentuk karena adanya perubahan bentuk permukaan bumi yang disebabkan oleh tingkah laku air di permukaan. Berdasarkan hasil analisis bentuk topografi pada peta geomorfologi, kawasan silokek ini memiliki 2 satuan bentuk lahan asal Fluvial antara lain:

a) Dataran Aluvial merupakan dataran yang terbentuk akibat proses-proses geomorfologi yang didominasi oleh tenaga eksogen antara lain iklim, curah hujan, angin, jenis batuan, topografi, suhu, dan sebagainya yang akan mempercepat proses plapukan. Kawasan ini termasuk daerah hulu sungai yang berarus relatif deras sehingga banyak terjadi pengikisan terhadap batuan yang ada disekitarnya. Dari pengikisan tersebut banyak batuan sedimen dan batuan metamorf yang mengendap dipinggiran sungai. Hasil endapan sedimentasi tersebut ada yang berukuran kerikil hingga lempung, tetapi lebih dominan bertekstur lempung dan ukuran kerikil biasanya lebih dominan asal batuan metamorf yang terkikis. Dan juga terdapat endapan sisa batu bara disana karena aliran sungai Batang Kuantan di silokek adalah cabang dari sungai ombilin yang batuannya terkikis lalu bertransportasi sampai ke sungai Batang Kuantan. Pada peta kawasan silokek ditandai warna biru muda.

b) Channel Bar adalah salah satu jenis dari satuan bentuk lahan Bar Deposit. Endapan ini berada di tengah alur sungai. Pada peta kawasan silokek ditandai warna merah.

\section{Bentuk lahan asal Denudasional}

Bentuk lahan asal Denudasional terbentuk akibat proses pengelupasan batuan induk yang telah mengalami proses pelapukan kemudian batuan yang telah lapuk tersebut dipindahkan oleh gaya gravitasi atau pencampkan batuan yang materialnya bergerak menuruni lereng akibat pengaruh gravitasi. Berdasarkan hasil analisis bentuk topografi pada peta geomorfologi, kawasan silokek ini memiliki 3 satuan bentuk lahan asal denudasional antara lain:

a) Bukit sisa merupakan bentuk lahan dengan karakteristik bagian depan (dinding) suatu pegunungan ngan atau perbukitan mundur akibat proses denudasi lereng kaki (footslope) bertambah lebar secara terus menerus sehingga meninggalkan bentuk sisa dengan lereng dinding bukit sisa curam, dapat terjadi pada pegunungan atau perbukitan terpisah maupun pada sekelompok pegunungan atau perbukitan dan umumnya mempunyai bentuk membulat. Pada peta kawasan silokek ditandai warna coklat pekat.

b) Perbukitan denudasional mempunyai topografi berbukit dan bergelombang dengan lereng berkisar antara $15-55 \%$ dengan perbedaan tinggi relief 50-500 m yang umumnya terkikis sedang hingga kecil tergantung pada kondisi litologi, iklim dan vegetasi penutup sehingga membentuk kenampakan relief yang tidak begitu terjal. Pada peta kawasan silokek ditandai warna coklat muda.

c) Lereng kaki merupakan bentuk lahan dengan bentukan memanjang dan relatif sempit dan terletak di kaki suatu pegunungan/perbukitan dengan topografi landai hingga berombak dan mempunyai lereng hingga lembut (nearly flat to 
gantle) dan hingga sedikit terkikis. Pada peta kawasan silokek ditandai warna hijau muda.

4. Bentuk lahan asal Karst

Dalam hasil pengamatan kami tentang bentang lahan karst dikawasan silokek, dapat kita klasifikasikan ke dalam tipe-tipe karst antara lain:

a) Klasifikasi berdasarkan perkembangannya menurut Cvijc, kawasan silokek masuk kedalam tipe Merokarst. Karena tipe ini berkembang dibatu gamping yang relatif tipis dan tidak berkembang, evolusi relatif lambat, erosi lebih dominan dibanding dengan pelarutan dan sungai permukaan dan dibawah permukaan dapat dengan mudah diidentifikasi dan drainase bawah tanah yang terhambatoleh lapisan imperemeable.

b) Klasifikasi berdasarkan pada iklim menurut Sweeting, kawasan silokek masuk kedalam tipe turmkarst. Tipe ini dicirikan oleh bukit-bukit dengan lereng terjal, biasannya ditemukan dalam kelompok yang dipisahkan satu sama lain dengan sungai atau dataran aluvial. Distribusi dan sebaran menara pada umumnya di kontrol oleh kekar atau sesar. Untuk lebih jelas lagi dapat dilihat di peta diatas.

Ada kawasan silokek yang dijadikan destinasi wisata yaitu Ngalau Talago. Ngalau talago adalah sebuah goa yang berada di atas bukit dengan kemiringan sudut 700, di dalam gua terdapat danau sehingga terlihat seperti telaga. Ngalau Talago terbentuk akibat adanya proses pelarutan oleh air yang berada di permukaan tanah lalu diperbesar oleh proses erosi yang mengikuti suatu jaringan retakan pada batuan. Air yang masuk ke jaringan retakan batuan tersebut masuk kedalam goa dan tergenang ke bawah permukaan goa, dan juga banyak terdapat stalaktit dan stalakmit akibat tetesan pelarutan tersebut.

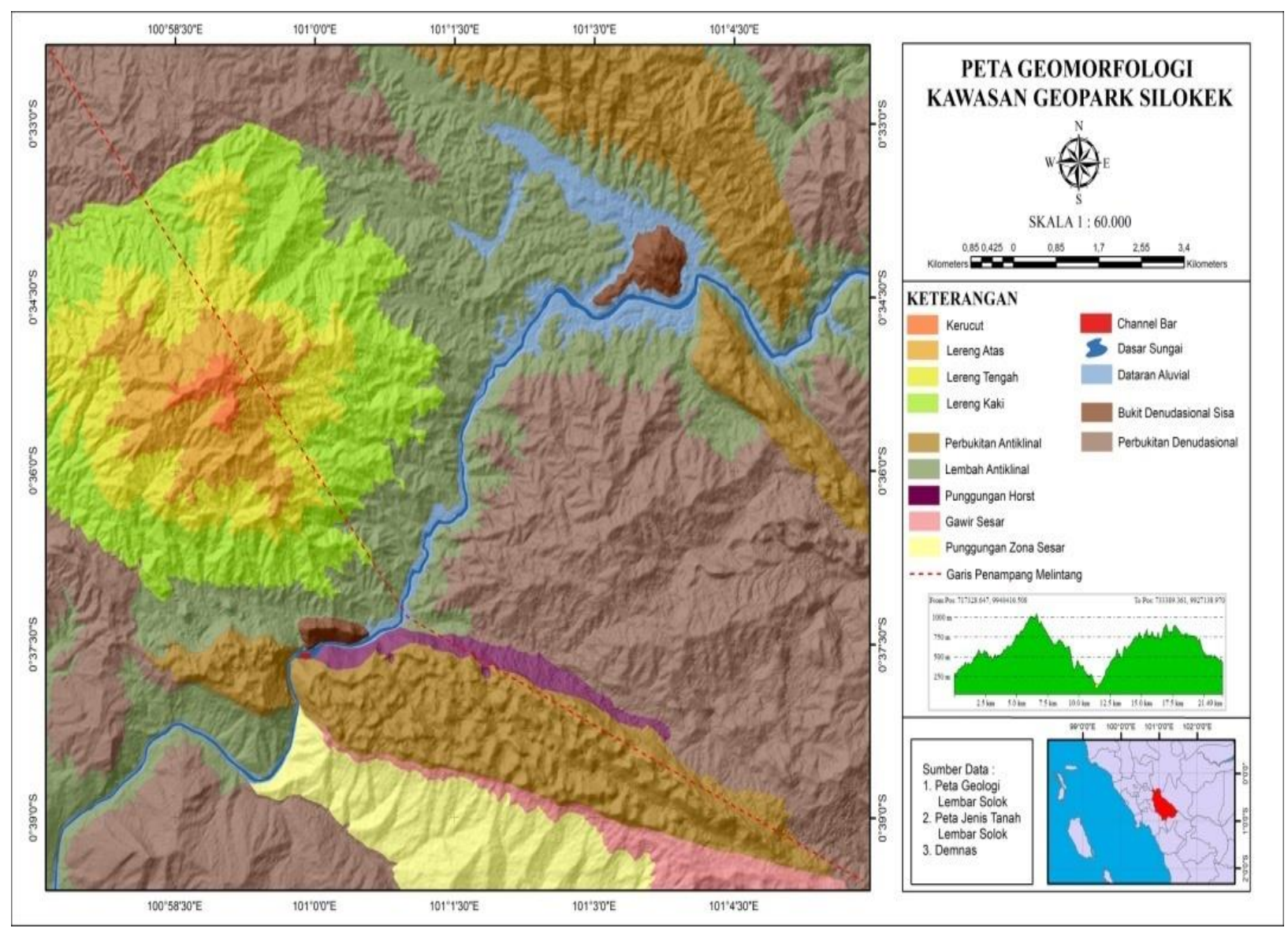

Gambar 2. Peta Geomorfologi Kawasan Geopark Silokek

(Sumber : Analisis Data, 2019) 


\section{B. Proses pembuatan peta 3D Geomorfologi} Geopark Silokek

Pembuatan Peta 3D Geomorfologi menggunakan skema Overlay dari data DEM yang diekstraksi sehingga menghasilkan bentukan 3D (Gambar 3), hasil bentukan tersebut akan ditimpal pada data SHP Geomorfologi sehingga akan menghasilkan Peta 3D Geomorfologi kawasan Geopark Silokek (Gambar 4). Kegunaan model 3D sangat penting dalam analisa bentangan lahan yang terdapat pada kawasan tersebut sehingga informasi yang didapatkan lebih akurat karena dapat melihat bentukan 3 dimensi. Dari hasil pengolahan tersebut maka dihasilkan peta 3D Geopark Silokek.

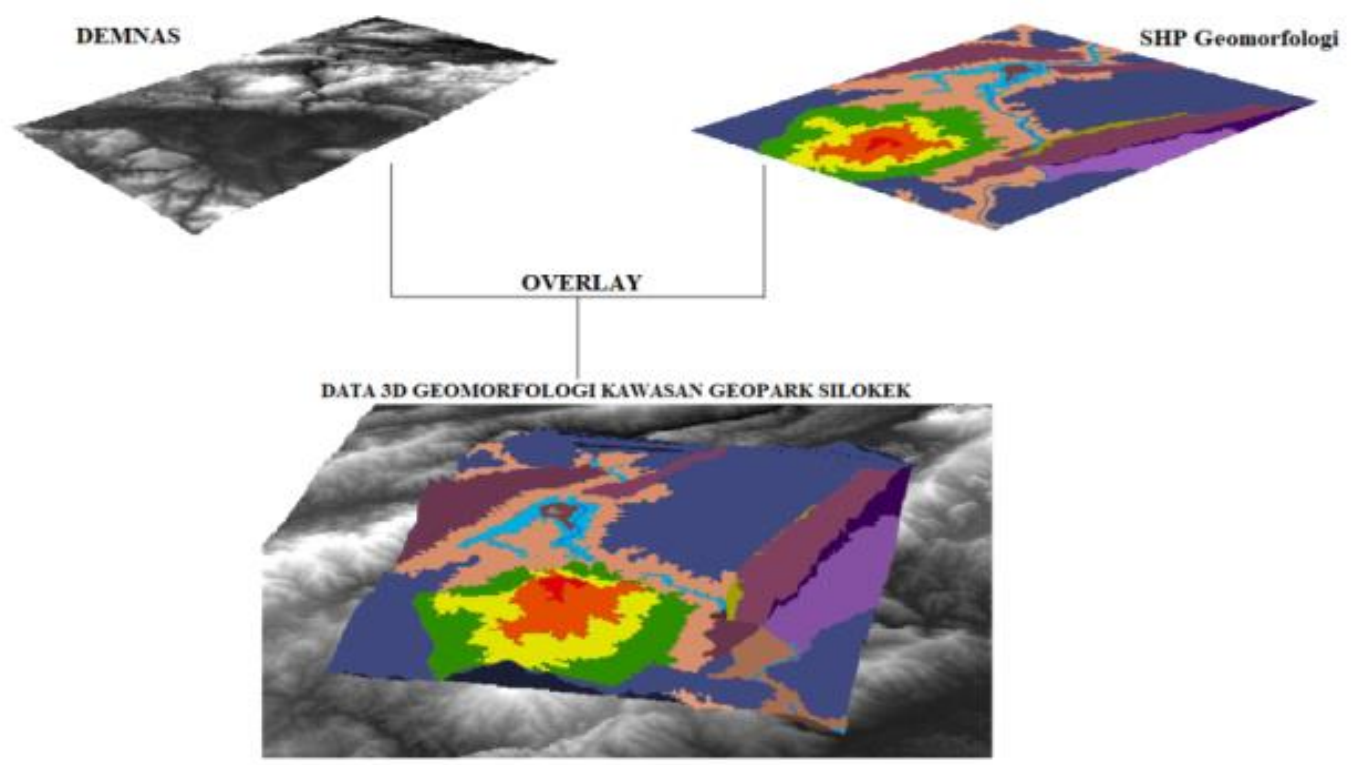

Gambar 3. Skema pembuatan peta 3D Geomorfologi kawasan Geopark Silokek (Sumber : Analisis Data, 2019)

\section{PETA 3D GEOMORFOLOGI KAWASAN GEOPARK SILOKEK}

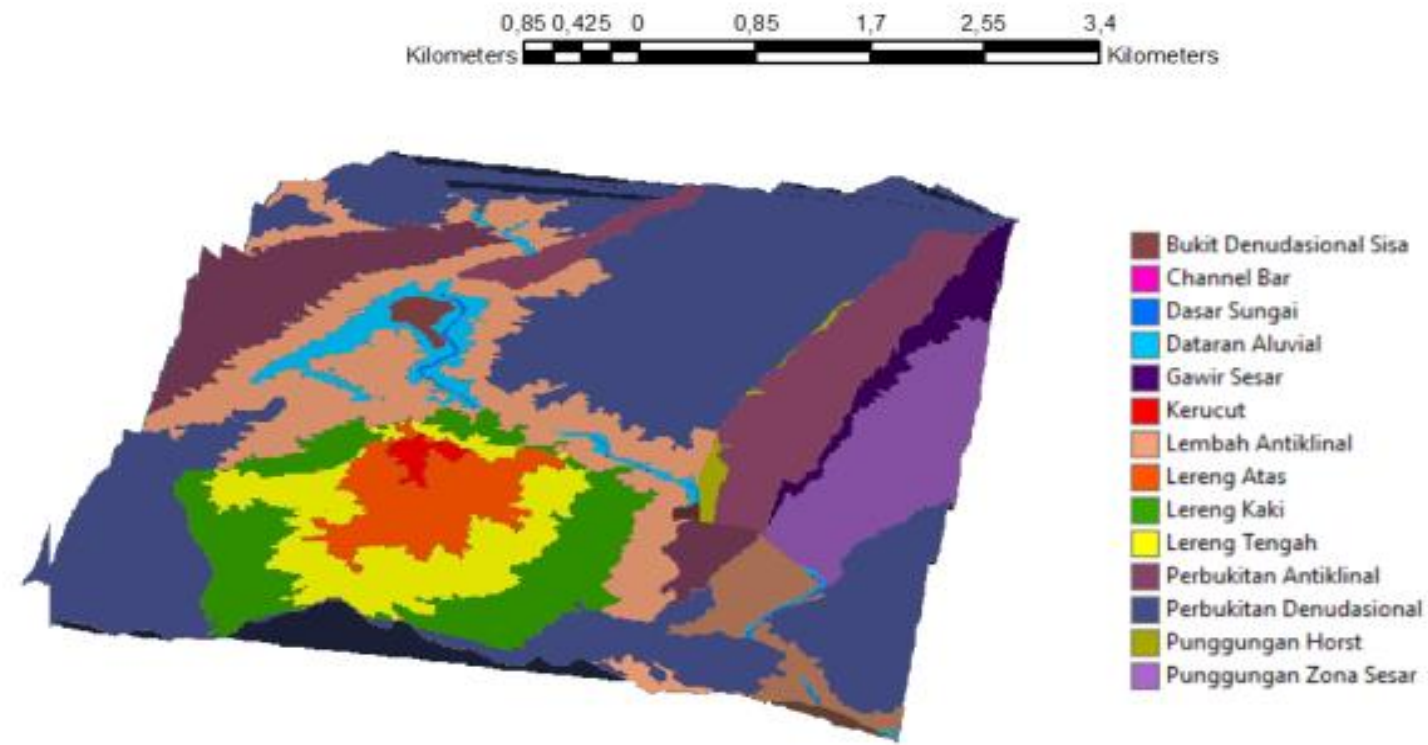

Gambar 4. Peta 3D Geomorfologi Kawasan Geopark Silokek (Sumber : Analisis Data, 2019) 


\section{SIMPULAN}

Pengunaan data Digital Terrain Model bukan hanya sekedar menampilkan informasi elavansi saja namun juga dapat membuat pemodelan 3D yang dikombinasikan dengan data Citra Spot 6 sehingga menghasilkan Peta 3D kenampakan Fisiografis ataupun dikombinasikan dengan SHP Peta Geomorfologi yang dari awalnya peta dalam bentuk 2D (Datar) dapat dibuat dalam model 3D sehingga dalam analisa kenampakan Geomorfologi jadi lebih mudah dan hasil nya lebih mudah dipahami oleh orang orang awam karena relief nya menggambarkan proses pembentukan yang terjadi. Dari hasil interpretasi menggunakan data DEM dan pengamatan dilapangan dapat disimpulkan bahwa kawasan Geopark silokek terdiri dari: (1) Bentuk lahan asal Struktural yang didalam nya terdapat blok perbukitan antiklinal, blok perbukitan patahan, dan Gawir Sesar; (2) Bentuk lahan asal Fluvial yang didalam nya terdapat Dataran Aluvial, dan Channel Bar; (3) Bentuk lahan Karst yang terbagi menjadi dua klasifikasi yaitu berdasarkan perkembangan dan iklim. Pemodelan 3D akan memperjelas kenampakan fisiografis yang terdapat di kawasan Geopark Silokek serta dapat menunjang potensi pariwisata di Geopark Silokek.

\section{DAFTAR PUSTAKA}

Balitbang Provinsi Sumatera Barat. (2018). "Pengembangan Kawasan Geopark Sumatera Barat dalam Kegiatan Survey Pemetaan dan
Perumusan Kebijakan Strategis Tahun 2018". Laporan Akhir Penelitian.

Fahrulian,dkk. (2016).Penetapan Metode Moving Average dan Digital Tirrain Model untuk Visualisasi Batrimetri 3 Dimensi Echosounder. Bogor.

Kusuma, Desi Widia. (2019). "Geopark Silokek Sijunjung menuju UNESCO Global Geopark”. Jurna Pembangunan Negeri, 4(1), 17-32.

Pemerintahan Kabupaten Sijunjung. (2018). "Geopark Silokek - Sijunjung Sumatera Barat : Dokumen Pengusulan Menjadi Geopark Nasional dan Keanggotaan pada Jaringan Geopark Nasional Indonesia (Dossier Silokek).

Satya, Octavianus Cakra.(2001)."Rancangan Teknik Interpolasi Jst- Langsung Global Pada Digital Terrain Model".Jurnal penelitian Sains,(9),110-119.

Surat Keputusan Bupati Sijunjung Nomor : 188.45/404/KPTS-BPT-2016 tentang Penetapan Kawasan Wisata Strategis dan Destinasi Pariwisata di Kabupaten Sijunjung.

Suharini, Erni, Abraham Palangan. (2014). “ Geomorfologi : Gaya, Proses dan Bentuk Lahan". Yogyakarta: Penerbit Ombak.

UNESCO. (2006). "Guidelines and Criteria for National Geoparks seeking UNESCO's assistance to join the Global Geoparks Network (GGN)". 